\title{
- Uso de citologia por impressão nas doenças oculares externas no homem, bovino e equiino
}

\section{Use of impression cytology in extern
diseases of man, cattle and borses}

* NoemeSousa Rocha' ${ }^{1}$-CRMV-SP- n $^{0} 5869$

Caio Henrique Paganini Burini' ${ }^{2}$-CRMV-SP- $\mathrm{n}^{0} 11280$

LucianaSousa de Albuquerque Lima ${ }^{3}$

Roberto Calderon Gonçalves ${ }^{4}$ - CRMV-SP- $\mathrm{n}^{0} 1713$

Armen'Thomassian'-CRMV-SP- n $^{0} 1113$

Amélia Kamegasawa - CRM-SP- ${ }^{0} 29046$

1 Profa. Ass. Dra. do Departamento de Clínica Veterinária - FMVZ- Unesp/Botucatu.

2 Pós-Graduando - FMVZ- Unesp/Botucatu.

${ }^{3}$ Acadêmica do $5^{\circ}$ ano de Medicina Veterinária- FMVZ- Unesp/Botucatu.

${ }^{4}$ Prof. Ass. Dr. do Departamento de Clínica Veterinária - FMVZ- Unesp/Botucatu.

${ }^{5}$ Prof. Titular do Departamento de Cirurgia e Anestesiologia Veterinária- FMVZ- Unesp/Botucatu.

${ }^{6}$ Profa. Ass. Dra. do Departamento de Oftalmologia, Laringologia e Cirurgia de Cabeça e Pescoço - FMB - Unesp/Botucatu.

\section{RESUMO}

A técnica convencional de citologia por impressão, substituindo-se a espátula por acetato de celulose, foi usada para diagnosticar lesões da superfície ocular externa do homem ( 10 homens/10 mulheres), bovino e eqüino (10 machos/10 fêmeas, respectivamente). Para tal, o acetato de celulose foi fragmentado em fitas, pressionado por 2 a 3 segundos, na superfície ocular externa de cada paciente. Posteriormente, o material foi corado pelo método de Giemsa e pelo de Shorr. Assim, diagnosticaram-se processos inflamatórios e neoplásicos. O método mostrou-se útil no auxílio das lesões oftalmológicas do homem e dos animais.

Palavras-chave: citologia impressão, olho, homem, bovino, equino.

\section{Introdução}

$A$ esfoliação dos epitélios foi a base das investigações de PAPANICOLAOU apud MADER et al. (1990); mas um aspecto que surpreende ao estudioso de sua importante obra é a ausência de pesquisas referentes aos olhos. WILHELM WERNECK apud MADER et al. (1990) com auxílio de uma espátula, descreve, pela primeira vez em oftalmologia, os aspectos microscópicos dos exsudatos conjuntivais num processo inflamatório agudo. Por se tratar de um valioso procedimento para investigar doenças oculares externas, vários oftalmologistas adotaram o método. Posteriormente, MADER e STULTING, (1990) e SPEIRS, (1999), utilizando o mesmo método, defrontam com problemas, tais como: requer imobilização adequada do paciente para assegurar que lesão adicional não seja produzida por movimento súbito e, além disso, a presença de artefatos 


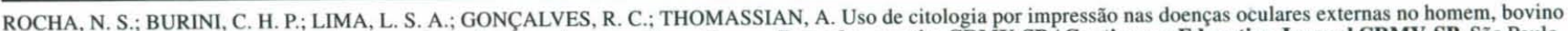

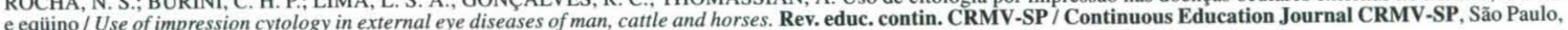
e eqüino / Use of impression cytology in extc

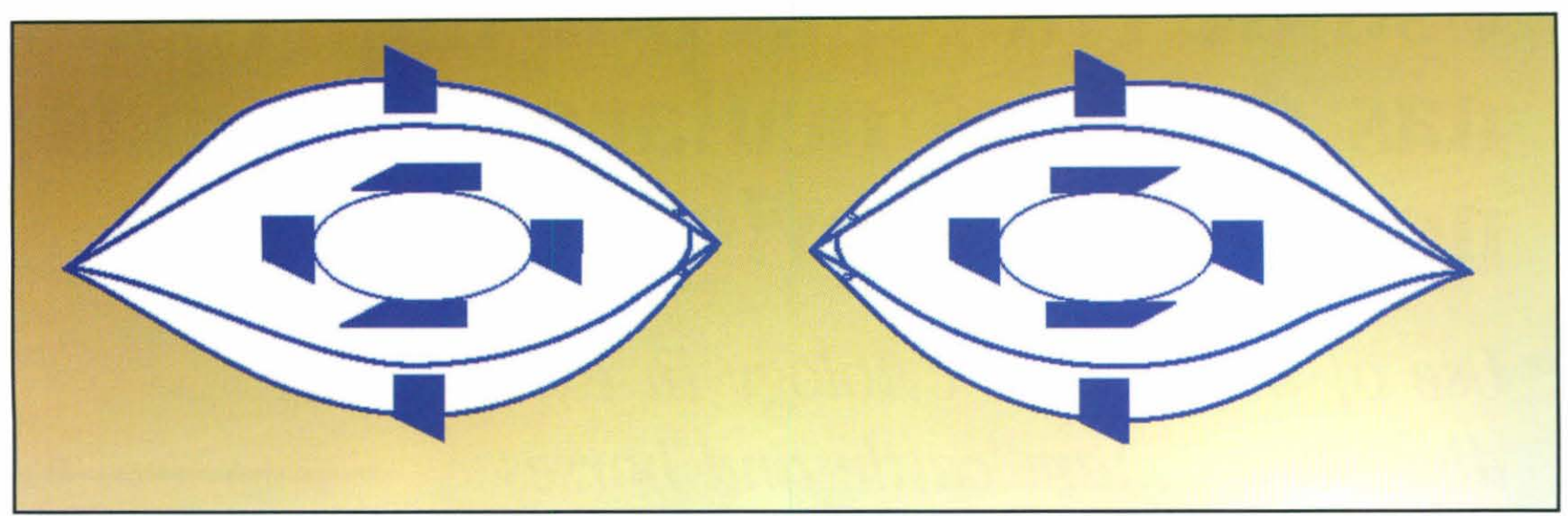

Figura 1. Esquema de orientação da impressão (TSENG, 1985).

resultantes do ressecamento das células, antes mesmo de serem fixadas.

A citologia por impressão da conjuntiva ocular é um método útil não invasivo de avaliação de lesões oculares externas, já bem estabelecido entre os oftalmologistas. A técnica foi desenvolvida desde a descoberta por EGBERT et al. (1977) de que células da camada epitelial externa do olho podem ser removidas pela aplicação do papel de filtro, e o de acetato de celulose, para avaliar diversas condições de comprometimento da superfície ocular (TSENG, 1985; MASKIN e BODE, 1986). Por exemplo, localizar anatomicamente a conjuntiva e o bulbo, quantificar a densidade de células caliciformes, "estadiar" metaplasia escamosa, diferenciar afecções bacterianas, virais, alérgicas, degenerativas ou tumorais (NELSON e WRIGHT, 1984; TSENG, 1985; PARIDAENS et al., 1992; NOLAN et al., 1994; SPEIRS, 1999). Apesar das vantagens claramente observadas na citologia de impressão, essa metodologia é pouco utilizada em Medicina Humana e em Medicina Veterinária, especialmente em nosso meio.

No presente trabalho, as lesões oculares externas no homem, bovinos e eqüinos foram avaliadas pelo exame citológico por impressão, utilizando-se membrana celulose regenerada (OE67- 0,45 $\mu \mathrm{mX} 47 \mathrm{~mm}$ de diâmetro).

\section{Material e Métodos}

\section{Homem}

No Ambulatório de Córnea, Doenças Externas Oculares e Lentes de Contato da Oftalmologia do Hospital das Clínicas da Faculdade de Medicina-Unesp-Botucatu, foram atendidos 20 pacientes: 10 homens e 10 mulheres com sinais clínicos de doenças oculares externas. Após a permissão dos pacientes para a realização do exame (Conselho de Ética), a conjuntiva ocular foi dividida em segmentos: conjuntiva palpebral e bulbar, direito e esquerdo, superior e inferior (Figura 1). Nesses locais, o papel filtro $0 \mathrm{E} 67(0,45 \mu \mathrm{mX} 47 \mathrm{~mm}$ de diâmetro) foi pressionado por 2 a 3 segundos e o material obtido foi distendido em lâminas histológicas.

\section{Bovinos e Eqüinos}

Nos Ambulatórios de Clínica e Cirurgia de Grandes Animais - FMVZ-Botucatu, foram avaliados 40 animais com sinais clínicos de lesões oculares, dos quais 20 bovinos (10 machos e 10 fêmeas) e 20 eqüinos (10 machos e 10 fêmeas). A identificação e coleta de material seguiram os mesmos critérios estabelecidos para o homem.

\section{Procedimentos Citopatológicos}

O material coletado, do homem e dos animais, foi corado pelo método de Giemsa e pelo de Shorr. A leitura das lâminas foi realizada em microscópio óptico, seguindo os critérios de aumento: $100 \mathrm{X}$ para avaliação da celularidade e qualidade da coloração; 200X para características de esfoliação (células inflamatórias, epiteliais, displásicas, neoplásicas, entre outras) e, por fim, o de 400X, observando-se as células individualmente e comparando-as entre si, além do padrão de núcleo, de citoplasma e de cromatinas. Foi também levada em consideração a presença de muco, fibrina e microorganismos. As lesões foram diagnosticadas de acordo com o local anatômico, as alterações morfológicas das células epiteliais, as células inflamatórias e os fenômenos exsudativos e produtivos, a saber:

- conjuntivite aguda quando demonstravam neutrófilos e macrófagos, havendo eosinófilos quando fosse alérgica a etiologia em causa, sem apresentar alterações na morfologia das células epiteliais; 
- conjuntivite crônica, quando apresentavam células mononucleares, predominando linfócitos e com observação de alterações na morfologia das células epiteliais;

- cerato-conjuntivite seca, na presença de produção de muco e/ou aumento das células caliciformes;

- neoplasia, quando as células epiteliais exibiam atipias já bem estabelecidas para o processo tumoral (Figura 1 e Tabela 1$)$.

Posteriormente, os dados foram correlacionados com hipóteses clínicas, nas espécies e entre as espécies analisadas.

\section{Resultados}

A técnica foi bem aceita tanto pelo homem quanto pelos animais e foi possível remover número suficiente de células da superfície ocular externa, permitindo, portanto, o diagnóstico das lesões (Tabela 1 e Figuras 2, 3 e 4). Não foi verificada diferença estatística entre e dentre as espécies, quanto à predisposição anatômica, nem quanto aos tipos de lesões estudadas (Tabela 1).

\section{Discussão e Conclusão}

Há cerca de 20 anos, o exame citológico por impressão tem sido utilizado com sucesso na identifi- cação de várias enfermidades (BELFORT, 1981; NELSON e WRIGHT, 1984; PARIDAENS et al., 1992). Em virtude disso, esse trabalho propôs-se a testar a eficiências da técnica para estudar lesões oculares externas, visto que, no ambulatório médico e médico veterinário da UNESP de Botucatu, essa técnica não era empregada, apesar da incidência elevada de lesões oftalmológicas.

A citologia por impressão da superfície externa ocular promove informação superior em relação a quaisquer outros métodos convencionais, sobre a localização anatômica de cada segmento com suas respectivas células epiteliais e outros componentes celulares, facilitando, desta forma, o diagnóstico das lesões (TSENG, 1985). Os resultados obtidos por este trabalho estão de acordo com esse autor, visto que, no material obtido por essa técnica, foi possível diagnosticar as lesões e, além disso, não houve complicações para os pacientes (homem e animais). Ao contrário, em algumas situações a simples coleta do material atuou como diagnóstico e tratamento, em particular naqueles indivíduos com ceratoconjuntivite seca, em que a simples retirada de células epiteliais mortas estimulou as células das camadas mais profundas a se replicar. Fato este que foi relatado pelos clínicos quando reavaliavam os pacientes (homem e animais), no re-

Tabela 1. Incidência de lesões oculares externas no homem, bovino e eqüino, verificadas por meio de citologia por impressão com membrana de celulose.

\begin{tabular}{|c|c|c|c|c|c|c|}
\hline Número/Espécie & \multicolumn{2}{|c|}{10 Homens } & \multicolumn{2}{|c|}{10 Bovinos } & \multicolumn{2}{|c|}{10 Equinos } \\
\hline Local anatômico/ lesão/Sexo & ऽ & 우 & $\hat{\jmath}$ & 우 & $\hat{\jmath}$ & q \\
\hline $\begin{array}{l}\text { Conjuntiva } \\
\text { Conjuntivite aguda } \\
\text { Conjuntivite crônica } \\
\text { Conjuntivite alérgica } \\
\text { Carcinoma }\end{array}$ & $\begin{array}{l}2 \\
1 \\
2\end{array}$ & $\begin{array}{l}2 \\
1 \\
1\end{array}$ & $\begin{array}{l}4 \\
1 \\
1\end{array}$ & $\begin{array}{l}5 \\
2\end{array}$ & 7 & $\begin{array}{l}6 \\
1\end{array}$ \\
\hline $\begin{array}{l}\text { Bulbo } \\
\text { Ceratite aguda } \\
\text { Ceratite crônica }\end{array}$ & $\begin{array}{l}1 \\
2\end{array}$ & $\begin{array}{l}1 \\
1\end{array}$ & 2 & 1 & & \\
\hline $\begin{array}{l}\text { Conjuntiva + Bulbo } \\
\text { Ceratoconjuntivite seca } \\
\text { Ceratoconjuntivite alérgica } \\
\text { Ceratoconjuntivite aguda }\end{array}$ & $\begin{array}{l}1 \\
1\end{array}$ & $\begin{array}{l}2 \\
1 \\
1\end{array}$ & 1 & 2 & 3 & 2 \\
\hline Total de lesões por espécie e sexo & 10 & 10 & 10 & 10 & 10 & 10 \\
\hline
\end{tabular}




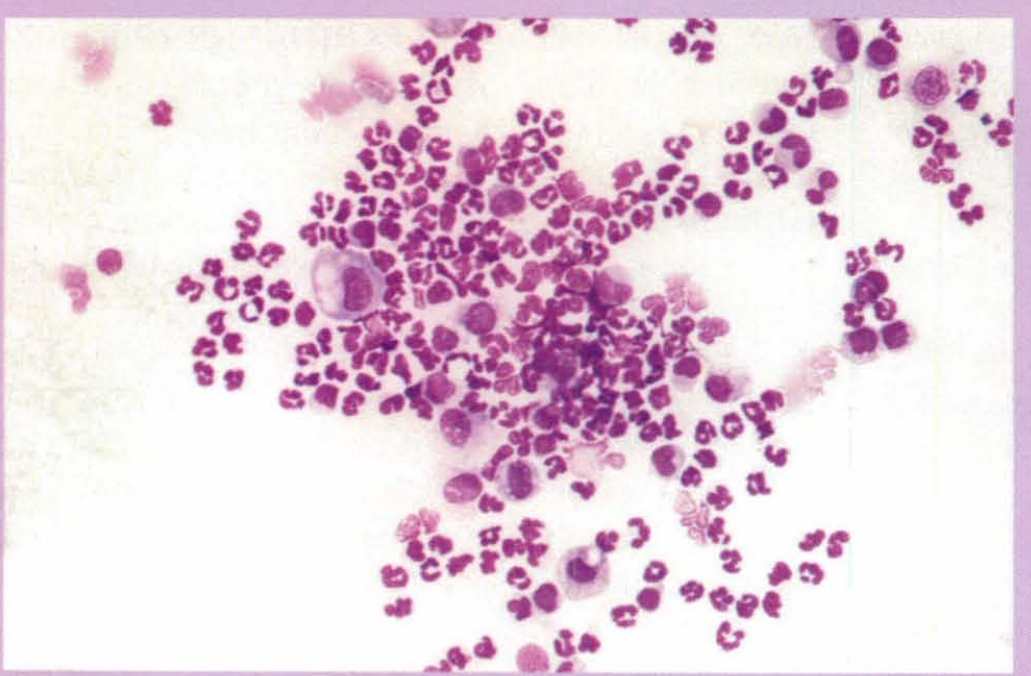

Figura 2. Bovino. Impressão. Conjuntivite aguda. Giemsa 200X

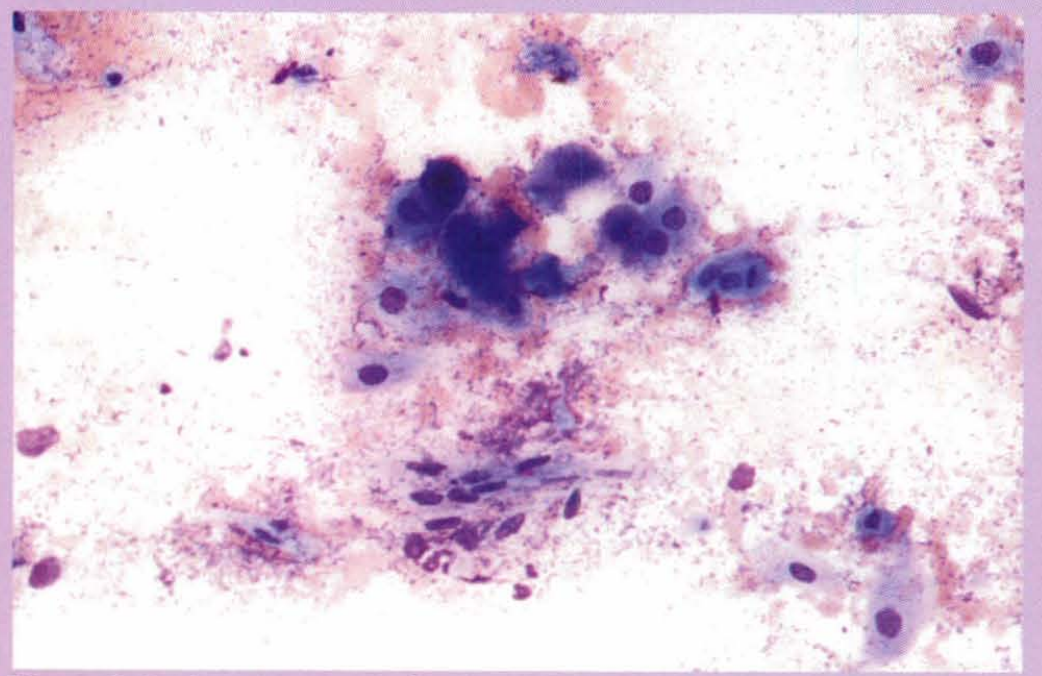

Figura 3. Bovino. Impressão. Carcinoma de conjuntiva. Giemsa 200X

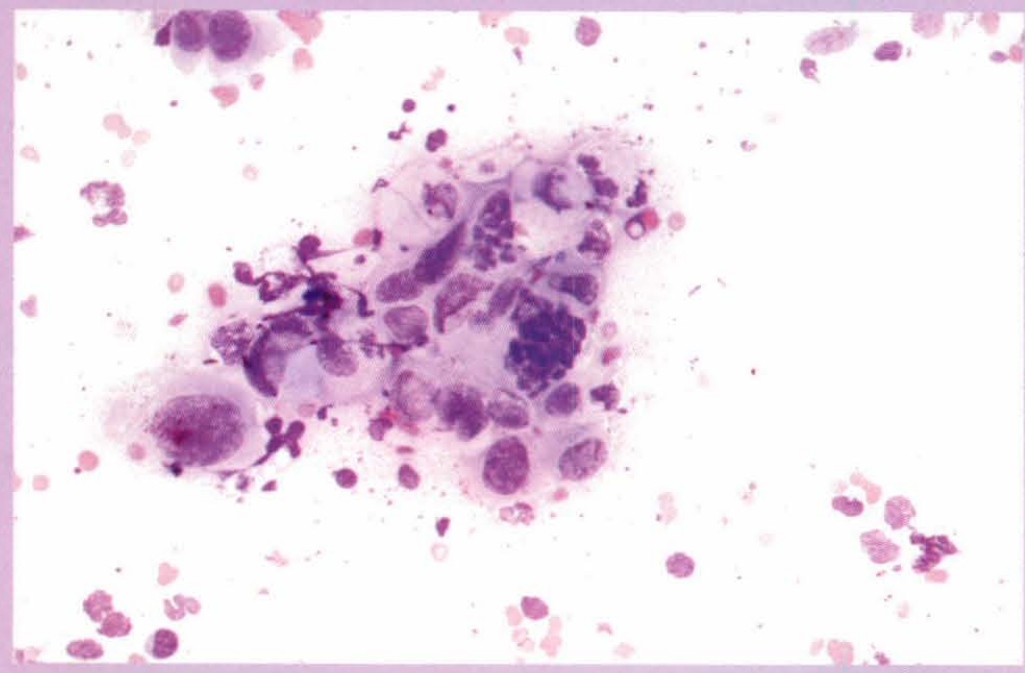

Figura 4. Eqüino. Impressão. Ceratoconjuntivite seca. Giemsa 200X torno. Quando se comparam as lesões oculares por espécies, apesar da maior incidência de lesões inflamatórias, verificase que outras enfermidades foram diagnosticadas por meio do exame citológico por impressão.

Apesar de os dados estatísticos não demonstrarem alterações significativas para nenhum dos tópicos analisados, é importante ressaltar que houve um predomínio de lesões de natureza inflamatória em todos os segmentos da superfície ocular externa estudada, tanto no homem como nos animais. Estes dados estão de acordo com os de OSTLER et al. (1987). Comentam ainda esses autores da relativa negligência dos oftalmologistas sobre o assunto.

Muitos instrumentos e técnicas estão disponíveis para a mais completa ou detalhada avaliação dos olhos dos animais, mas a disponibilidade desse material é geralmente limitada para os veterinários oftalmologistas (MOORE, 1993). Segundo BELFORT (1981), em grande número de casos, o exame citológico da superfície ocular externa pode fornecer dados suficientes para diferenciação entre afecções bacterianas, virais, alérgicas, degenerativas ou neoplásicas. Deve-se ressaltar que a localização e os tipos de doenças oculares entre as espécies foram relativamente similares. Portanto, o exame citológico por impressão utilizando o papel filtro pode ser útil no diagnóstico de lesões da superfície externa ocular do homem e dos animais. Além disso, pode contribuir indiretamente para tratar as lesões, tais como o glaucoma, o descolamento de retina, entre outras, pelo fato de essas lesões predisporem a agentes infecciosos externos e, conseqüentemente, desenvolverem processos inflamatórios na superfície externa do olho, agravando mais o quadro.

No futuro, oftalmologistas médicos e veterinários habituar-se-ão a utilizar a citologia por impressão como auxílio diagnóstico nas enfermidades da conjuntiva e do bulbo ocular de seus pacientes por preencher os requisitos de facilidade e simplicidade de execução, causando o mínimo incômodo para o paciente. 


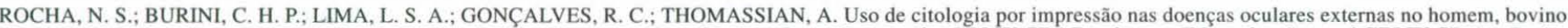

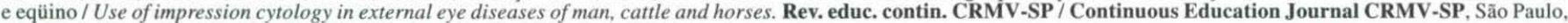
volume 4 , fascículo 1, p. $03-07,2001$.

\section{SUMMARY}

The conventional imprint cytology assay for diagnosing ocular surface disorders was modified by using cellulose acetate strips cuted in an asymmetrical shape and stained by Giemsa and Shorr. Using this technique we studied inflammatory and neoplasic processes in human (10 men/ 10 women), bovine and equine (10 cows/10 bulls, respectively). The cellulose acetate strips were pressed for about 2-3 seconds over the designed area. Thus this modified impression cytology technique may be helpful in diagnostic the ocular surface disorders.

Key words: cytology imprint, eye, human, bovine, equine.

\section{REFERÊNCIAS}

1. AZEVEDO, M. L. Citologia ocular. 1962. 88 f. Tese (Doutorado) - Faculdade de Medicina, Universidade de São Paulo.

2. BELFORT, R.; AlmadA, A. T.; TOMIMATSU, P. Doenças externas oculares. São Paulo: Roca, 1981. 109 p.

3. EGBERT, P.R.; LAUBER, S.; MAURICE, D.M. A simple conjunctival biopsy. American Journal Ophthalmology, n. 84, p. 789-801, 1977.

4. MADER, T. H.; STULTING, R. D. A new method of obtaining cells from the cornea and conjunctiva for cytologic study. Archives Ophthalmology, n. 108, p. 639, 1990.

5. MASKIN, S. L.; BODE, D. D. Electron microscopy of impression acquired conjunctival epithelial cells. Ophthalmology, n. 93, p. 1518-23, 1986.

6. MOORE, C. P. Diseases of the eye. In: MOORE, C. P. Ophthalmic examination techniques for food and fiber animals. Philadelphia: Saunders, 1993. P. 829-56.

7. NAIB, Z. M. Cytology ocular lesions. Acta Cytology, n. 16, p. 178-85, 1972.
8. NELSON, J. D.; WRIGHT, J. C. Conjunctival goblet cell densities in ocular surface disease. Archives Ophthalmology. n. 102, p. 1049-51, 1984.

9. NOLAN, G. R.; HIRST, L. W.; WRIGHT, R. G.; BANCROFT, B. J. Application of impression cytology to the diagnosis of conjunctival neoplasms. Diagnostic Cytopathologic, n. 11, p. 246-49, 1994.

10. OSTLER, H. B.; DAWSON, C. R.; OKUMOTO, M. Color atlas of infections and inflammatory disease of the external eye. Baltimore: Munich. 1987. 166 p.

11. PARIDAENS, A. D. A.; McCARTNEY, A. C. E.; CURLILING, O.M.; LYONS, C. J.; HUNGERFORD, J. L. Impression cytology of conjunctival melanosis and melanoma. British Journal of Ophthalmology, n. 76, p. 198-201,1992.

12. SPEIRS, V. C. O olho e seus anexos. In: SPEIRS, V. C. Exame clínico de eqüinos. Porto Alegre: Artmed, 1999. P. 249-67.

13. TSENG, S. C. G. Staging of conjunctival squamous metaplasia by impression cytology. Ophthalmology, n. 92, p. 728-33, 1985.

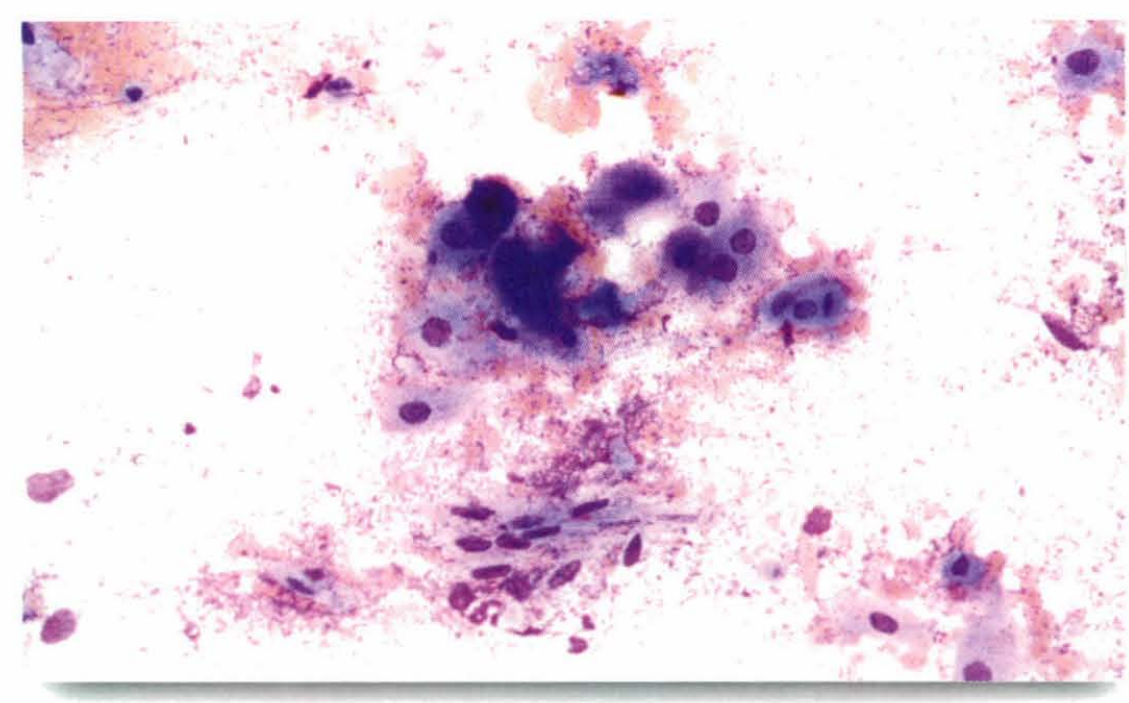

